\title{
DIGITALIZAÇÃO E HIGIENIZAÇÃO DA DOCUMENTAÇẨO NA DIVISÃO DE ARQUIVO DO DAP/PRODEGESP-UFSC
}

\author{
JOSÉ DA ROSA* \\ ELIANA MARIA DOS SANTOS BAHIA JACINTO** \\ DOUGLAS AGUIAR DAS NEVES ${ }^{* * *}$ \\ WILLIAM ADÃO FERREIRA PAIVA ${ }^{* * *}$
}

\begin{abstract}
RESUMO
Discussões teóricas sobre a informação e suas práticas fazem parte do universo acadêmico. A Ciência da Informação, que abarca a Arquivologia, a Biblioteconomia e a Museologia, abre um espaço nessa relação com cada área possuindo diferentes características, diálogos, cabendo aos alunos dessa área interdisciplinar conhecerem a natureza dos materiais componentes do acervo do Departamento de Administração de Pessoal, que tem como público-alvo os funcionários ativos, inativos e pensionistas. Cabe, também, aplicarem seus conhecimentos na Organização, Digitalização e Higienização da documentação na Divisão de Arquivo, tratarem a vivência entre a teoria e a prática, uma vez que possibilita a soma de esforços dentro da UFSC, que reconhece a importância da organização da documentação no arquivo institucional e desperta o caminhar do saber fazer. Estudantes passaram nos Concursos Públicos da UFSC e foram atuar na DARQ, observa-se que o trabalho tem gerado a ampliação de atuação na formação dessas áreas. Durante diversos anos, foram realizadas atividades de extensão e, a partir de 2005, com o currículo novo da Biblioteconomia, ocorre a implantação dos Trabalhos de Conclusão de Curso. Ao final do artigo, têm-se os resultados a serem alcançados e esperados.
\end{abstract}

PALAVRAS-CHAVE: arquivo; ciência da informação; digitalização; documentação; higienização.

\footnotetext{
* Bibliotecário e Graduando do Curso de Arquivologia na Universidade Federal de Santa Catarina.

** Professor do Curso de Arquivologia e Pós-graduação do depot CIN-UFSC.

** Bibliotecário.

**** Mestre em História pelo Programa de Pós-Graduação em História (Mestrado Profissional) da Universidade Federal do Rio Grande - FURG. Especialista em Gestão de Projetos, pela Universidade Norte do Paraná - UNOPAR. Arquivista da Universidade Federal de Santa Catarina - UFSC.
} 


\begin{abstract}
Theoretical discussions about information and its practices are part of the academic universe. The Information Science encompassing Archivology, Librarianship and Museology, open a space in this relationship with each area possessing different characteristics, dialogues, and it is up to the students of this interdisciplinary area, to know the nature of the material components of the collection of the Department of Personnel Administration, which has as target audience the active, inactive and pensioners. It is also necessary to apply their knowledge in the Organization, Digitization and Hygiene of the documentation in the Archive Division, to deal with the experience between theory and practice, since it allows the sum of efforts within the UFSC that recognizes the importance of organizing the documentation in the institutional archive and awakens the path of know-how. Students passed the Public Competitions of the UFSC and were working in the DARQ, it is observed that the work has generated the expansion of action in the formation of these areas. Extension activities were carried out for several years and from 2005, with the new curriculum of Librarianship, the implementation of the Course Completion Works takes place. At the end of the article, we have the results to be achieved and expected.
\end{abstract}

KEYWORDS: archive; information science; scanning; documentation; hygienization.

\title{
1 INTRODUÇÃO
}

A Ciência da Informação abarca a Arquivologia, a Biblioteconomia e a Museologia, sendo uma área interdisciplinar de espaço nas discussões teóricas sobre a informação e suas práticas. Cada área possui diferentes características, mas possibilita constantes diálogos. Essas questões estão presentes nas ações de ensino, pesquisa e extensões (tríade da universidade), em que os envolvidos se propõem a pensar e se posicionar sobre as reflexões que apontam para formas como se entende e explica o mundo da informação. As áreas de interesse e que são objeto de estudos na docência e investigação em busca de soluções e resultados requerem a inovação e a aplicação nos ambientes, de metodologias, mas, algumas vezes, estão separadas da teoria e prática. Cabe aos alunos dos referidos cursos de Biblioteconomia, Arquivologia, Museologia e Ciência da Informação conhecerem a natureza dos materiais componentes do acervo do Departamento de Administração de Pessoal - DAP. A Divisão de Arquivo - DARQ tem a função de receber e arquivar, no Arquivo Corrente, os documentos produzidos pelos servidores docentes e técnico-administrativos ativos e inativos e seus dependentes, bem como realizar a 
organização, o armazenamento e a disponibilização da documentação por meio da DARQ.

A conservação do arquivo do DAP requer ações de preservação, que são um conjunto de medidas e estratégias de ordem administrativa, política e operacional que contribuem direta ou indiretamente para a preservação da integridade dos materiais do arquivo da UFSC. Para as autoras Chagas e Bahia (2010, p. 51), é essencial que cada geração transmita, da melhor forma, às gerações vindouras os conhecimentos técnicos e científicos para a adequada preservação dos documentos. A conservação é um conjunto de ações estabilizadoras que visam desacelerar o processo de degradação de documentos ou objetos, por meio de controle ambiental e de tratamentos específicos. Cabe, portanto, encontrar soluções que permitam oferecer a melhor estabilidade ao suporte da maioria dos documentos no arquivo. Portanto, com frequência, não se pode eliminar totalmente as causas do processo de deterioração da massa documental. Certamente, existem possibilidades de diminuir consideravelmente seu ritmo através de prevenção: do ambiente, o manuseio, as intervenções, as higienizações e as embalagens. A lei 8.159 de 08 de janeiro de 1991 estabelece, em seu artigo $1^{\circ}$, que:

É dever do Poder Público a gestão documental e a proteção especial a documentos de arquivos, como instrumento de apoio à administração, à cultura, ao desenvolvimento científico e como elementos de prova e informação (BRASIL, 1991).

Geralmente, é difícil para uma instituição a contratação de profissionais especializados na área para desenvolver programas de conservação e preservação do acervo. O caminho alternativo está em colocar em prática as ações para que os alunos possam aplicar e aprender a serem competitivos e eficazes com as tecnologias da informação e de preservação de documentos. A percepção ética dos Arquivistas que compõem o quadro de pessoal permanente das universidades federais deve cumprir a da Lei de Acesso à Informação, 12. 527 de 18 de novembro de 2011 , que propõe em seu Art. $3^{\circ}$ :

Os procedimentos previstos nesta Lei destinam-se a assegurar o direito fundamental de acesso à informação e devem ser executados em conformidade com os princípios básicos da administração pública. 
Já o decreto 8.539 de 8 de outubro de 2015 dispõe sobre o uso do meio eletrônico para a realização do processo administrativo no âmbito dos órgãos e das entidades da administração pública federal. Ao transferirem informação para a sociedade, influenciam no discernimento e no comportamento social dos indivíduos. Firmam-se na ética do dever, desempenhando atividades na administração pública. $\mathrm{O}$ inciso II, do artigo $3^{\circ}$ destaca "promover a utilização de meios eletrônicos para a realização dos processos administrativos com segurança, transparência e economicidade".

O presente projeto de extensão Digitalização e Higienização da Documentação na Divisão de Arquivo do DAP/PRODEGESP/UFSC pretende oferecer oportunidades de pensar, aplicar e buscar novas práticas, encaminhar questionamentos, reflexões e discussões na área de Ciência da Informação, Arquivologia, Biblioteconomia e Museologia. Trata-se de uma vivência entre a teoria e a prática, uma vez que possibilita a soma de esforços dentro da UFSC, pois a Instituição reconhece e aceita a importância da organização da documentação no arquivo institucional e desperta o caminhar do saber fazer.

\section{HISTÓRICO DA DIVISÃO DE ARQUIVO (DARQ)}

A Divisão de Arquivo (DARQ) do Departamento de Administração de Pessoal (DAP) encontra-se localizada no Prédio da Reitoria I, no Bairro da Trindade, da Universidade Federal de Santa Catarina (UFSC). O Departamento está subordinado à PróReitoria de Desenvolvimento e Gestão de Pessoas (PRODEGESP). A missão da PRODEGESP tem como objetivo "auxiliar o Reitor em suas tarefas executivas na área de desenvolvimento e gestão de pessoas, almejando o fortalecimento das atividades de ensino, pesquisa e extensão, bem como um melhor nível de qualidade de vida no trabalho aos servidores docentes e técnico-administrativos em educação" (UFSC, 2017). A Pró-Reitoria de Desenvolvimento e Gestão de Pessoas é formada por três departamentos: Departamento de Administração de Pessoal (DAP); Departamento de Desenvolvimento de Pessoas (DDP); e Departamento de Atenção à Saúde (DAS). Para melhor entendimento, segue o organograma da PRODEGESP.

FIGURA 1 - Organograma da Pró-Reitoria de Desenvolvimento e 


\section{Gestão de Pessoas (PRODEGESP)}

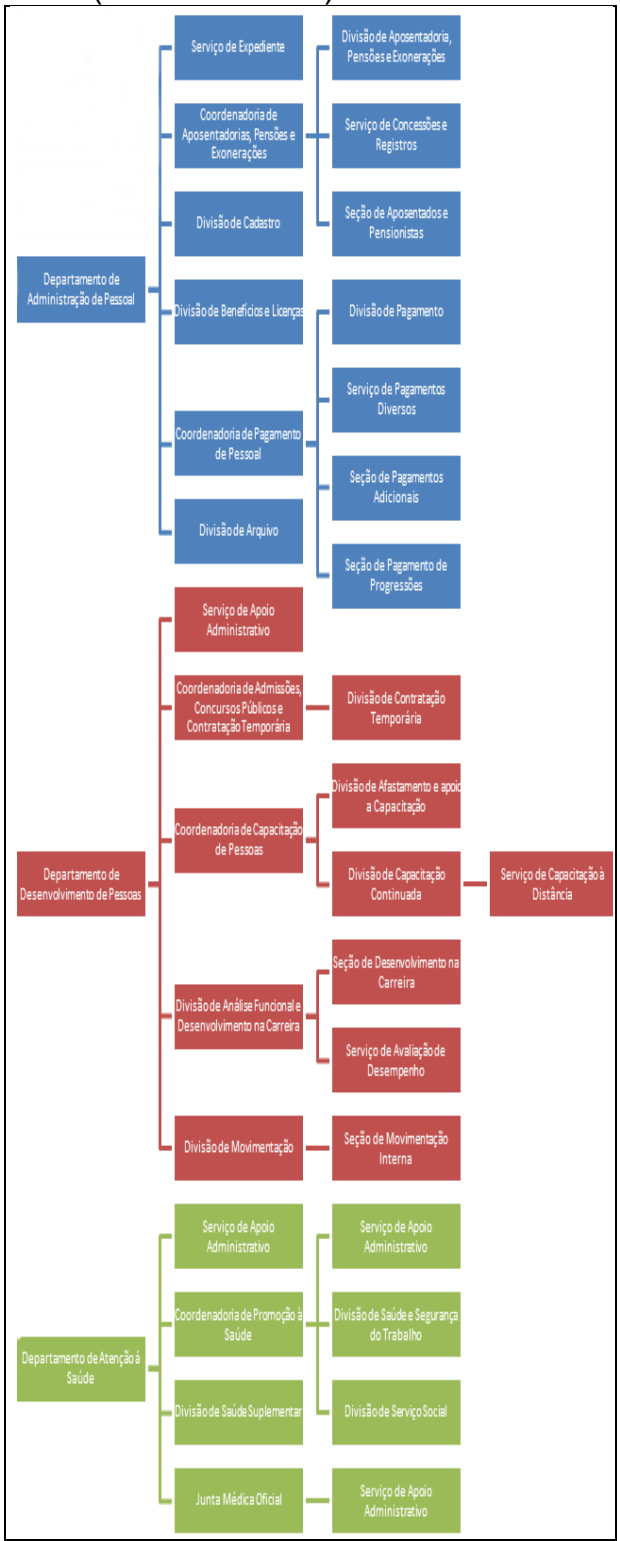

FONTE: Disponível em: <http://prodegesp.ufsc.br/apresentacao/organograma-prdhs/>. Acesso em: 11 out. 2017.

O Departamento de Administração de Pessoal tem como 
principal atividade desenvolver ações de administração de pessoal e gerenciar o processo de trabalho. A Divisão de Arquivo (DARQ) tem como função receber e arquivar, no Arquivo Corrente, os documentos produzidos pelos servidores docentes e técnicoadministrativos ativos e inativos e seus dependentes, bem como realizar o tratamento da informação, organização e disponibilização aos usuários. Segue a representação do organograma do Departamento de Administração de Pessoal com suas divisões e subordinações administrativas.

FIGURA 2 - Organograma do Departamento de Administração de Pessoal ${ }^{1}$.

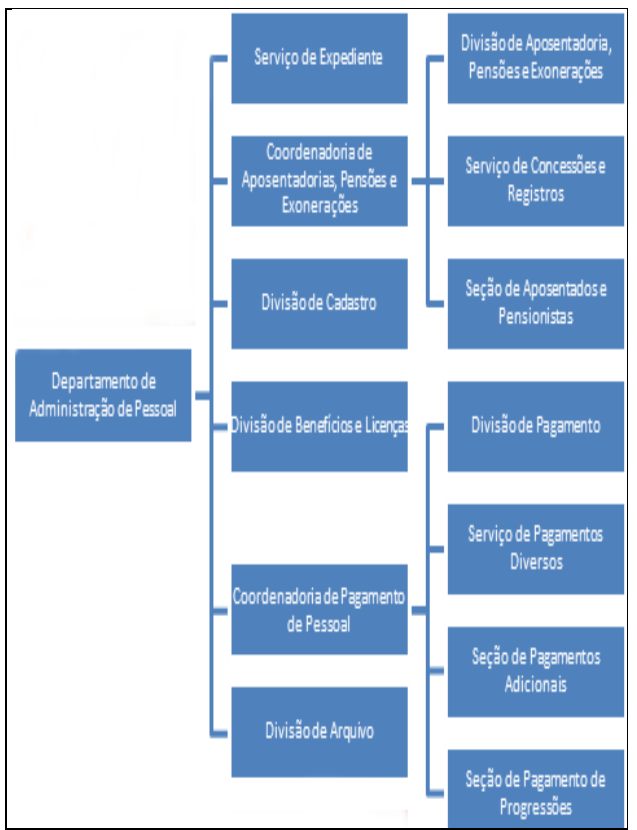

FONTE: Elaborado pelo autor partir de Organograma da PRODEGESP (2017).

Disponível em: <http://prodegesp. ufsc.br/apresentação /organograma-prdhs/>. Acesso em: 17 out. 2017.

Quanto ao histórico do Arquivo, este teve sua origem através

\footnotetext{
${ }^{1} \mathrm{O}$ organograma da DAP foi elaborado de acordo com as novas nomenclaturas de cada unidade administrativa, adquiridas com a nova gestão administrativa da Reitoria, a partir do organograma que se encontra no site da Pró-Reitoria de Desenvolvimento e Gestão de Pessoas. Disponível em:

<http://prodegesp.ufsc.br/apresentacao/organogram a-prdhs/>. Acesso em: 11 out. 2017.
} 
do crescente acúmulo da massa documental produzida e recebida ao longo dos anos pelo Departamento de Recursos Humanos da UFSC, que esteve subordinado ao Setor de Cadastro. Com o acúmulo de documentos e sem uma Organização Técnica Arquivística, a recuperação da informação ficava cada vez mais difícil. $O$ arquivo da DARQ vem passando por um momento de mudanças, tendo em vista as questões das Tecnologias da Informação, da Comunicação e da nova era social e informacional, a qual se apresenta na Ciência da Informação e na Sociedade da Informação.

A atuação do Departamento de Ciência da Informação (CIN) no Arquivo da DARQ vem desde os meados da década de 1990, ao realizar atividades como os Cursos de Capacitação aos servidores da UFSC, Trabalho Conjunto (Docentes do Departamento e Servidores) na Organização de Arquivos, Criação e Publicação da Tabela de Temporalidade (1995 e 2009) e, principalmente, na parceria em executar Projetos de Extensão, na oferta de bolsas aos alunos do Curso de Graduação em Biblioteconomia e, a partir de 2010, incluindo também alunos do Curso de Graduação em Arquivologia, sendo que, em abril de 2016, iniciaram as primeiras atividades de alunos do Curso de Graduação em Ciência da Informação. Esta parceria entre a Divisão de Arquivo (DARQ) e o Departamento de Ciência da Informação (CIN) em projetos de extensão iniciou-se em dezembro de 2006 e proporcionou a 108 estudantes a oportunidade de desenvolver atividades relacionadas à sua profissão futura.

Cabe destacar que, durante esses anos (2006-2018), alguns estudantes passaram nos Concursos Públicos da UFSC e foram atuar na DARQ. Conforme observa-se, o trabalho tem gerado a ampliação de atuação na formação dessas áreas. Neste momento, o encaminhamento do projeto visa formalizar as Atividades de Extensão e conta com o Técnico Administrativo Sr. Douglas Aguiar das Neves, formado em Biblioteconomia pela Universidade Federal de Santa Catarina (UFSC), que, atualmente, assume a Chefia da Divisão de Arquivo do Departamento. Juntamente com cinco (05) alunos dos Cursos mencionados, realiza-se a Higienização, a Preservação e o Uso da Informação Arquivística, sendo que todas essas temáticas encontram-se firmemente ancoradas nas ações do Departamento de Ciência da Informação da UFSC, o que, de certa forma, corrobora com a posição dos Cursos nesse domínio dos conhecimentos científicos das áreas. O Arquivo é caracterizado como Corrente, devido ao uso frequente dos documentos para os 
fins aos quais foram criados. É composto, principalmente, por pastas funcionais de servidores ativos da Universidade. Nessas pastas, encontram-se documentos como portarias, memorandos, boletim de ocorrência, processos administrativos, requerimentos, ficha funcional, ofícios, dentre outros documentos pertinentes à vida profissional do servidor na Universidade. Todas as caixas com a massa documental ficam localizadas em doze (12) estantes deslizantes e oito (08) estantes de ferro fixas. Também há dez (10) computadores de mesa, seis (6) scanners para a digitalização documental, duas (2) mesas para a higienização e sete (7) mesas para os computadores, nove (9) cadeiras de escritório, uma (1) máquina de visualizar fichas de microfilme e cinco (5) telefones. No que diz respeito a Recursos Humanos, há, no Arquivo, três (3) bolsistas do Curso de Graduação em Arquivologia, dois (2) bolsistas do Curso Ciência da Informação, três (2) Técnicos Administrativos e um (1) Arquivista.

Os usuários do Arquivo do Departamento de Administração de Pessoal são os servidores docentes e técnico-administrativos da Universidade Federal de Santa Catarina (UFSC). Estes são classificados como usuários internos do arquivo. De acordo com Cunha e Cavacanti (2008, p. 373), "Usuário interno é o usuário que frequenta o arquivo, já está familiarizado com o acervo ou banco de dados". Além desses usuários, o arquivo também apresenta usuários externos, segundo Cunha e Cavalcanti (2008, p. 373), "Usuário externo não pertence ao arquivo, porém tem autorização para utilizar". Esses usuários são compostos pela CGU Controladoria Geral da União, a qual realiza trilhas de auditoria interna para verificação de assuntos governamentais e, para isso, utiliza alguns documentos do arquivo, bem como documentos dos pensionistas e dos servidores efetivos que solicitam a documentação para resolver necessidades de interesse particular. Convém evidenciar que os usuários que utilizam com frequência o Arquivo Corrente são os usuários das Divisões internas do Departamento, pois necessitam, regularmente, consultar documentos para a tomada de decisão nas atividades administrativas de rotina. As metas da Gestão da Informação no Arquivo da DARQ visam contribuir com a Eficácia Administrativa da organização da UFSC, considerando, também, os outros usos em termos de permitir um Conhecimento Histórico da UFSC para Sociedade Catarinense.

\section{OBJETIVO GERAL}


O objetivo deste projeto é de caráter extensionista, aplicando conhecimentos na Organização, Digitalização e Higienização da Documentação na Divisão de Arquivo do DAP/PRODEGESP/UFSC.

\subsection{Objetivos específicos}

1. Usar os Instrumentos disponíveis para Organização, Preservação e Digitalização da documentação;

2. Desenvolver Práticas de Preservação no Arquivo Corrente e Intermediário;

3. Organizar os Arquivos Correntes e Intermediários da Repartição Pública Federal;

4. Empregar técnica de Digitalização e noções de Higienização na Documentação.

\section{METODOLOGIA}

A extensão universitária espera desenvolver um conjunto de atividades de caráter educativo, científico e tecnológico, envolvendo docentes, pesquisadores, discentes (bolsistas) e servidores técnicoadministrativos, que compõem as linhas de atuação do Núcleo de Pesquisas de Estudos em Arquivos Contemporâneos (NUPEAC), que visa contribuir para a Sociedade com pesquisa, ensino e extensão, participando com ações e reflexões e, em especial, contribui com a Reunião de Ensino e Pesquisa em Arquivologia (REPARQ) e no Fórum de Ensino e Pesquisa em Arquivologia (FEPARQ).

A pesquisa é documental e exploratória. O público-alvo são os funcionários ativos, inativos, e pensionistas DAP. A abordagem do problema é qualitativa e quantitativa quanto ao ponto de vista dos objetivos e procedimentos técnicos de uso das tecnologias de informação e comunicação disponíveis na DARQ, possibilitando a compreensão e o fortalecimento entre ensino, pesquisa e extensão. O projeto é realizado com o envolvimento de alunos, servidores e colaboradores envolvidos no seu desenvolvimento, pois o debate sobre informação no sentido prático é fundamental para o amadurecimento conceitual, no âmbito da Ciência da Informação.

\section{DEMONSTRAÇÃO DA RELEVÂNCIA ACADÊMICA E SOCIAL E}




\section{PÚBLICO-ALVO}

Durante diversos anos, foram realizadas atividades de extensão e, a partir de 2005, com o currículo novo da Biblioteconomia, ocorre a implantação dos Trabalhos de Conclusão de Curso.Conforme pesquisas no processo cognitivo (REYZABAL, 1999), as vantagens de discutir a teoria e colocar em prática são que o estudante apreende melhor e retém o aprendizado por mais tempo. Entre os exemplos, temos a realização dos Trabalhos de Conclusão de Cursos: NEVES, Douglas Aguiar das. A ergonomia no Arquivo do DAP na Universidade Federal de Santa Catarina, 2010. TCC (Curso de Biblioteconomia); com professora orientadora Prof. Eliana Bahia; FACHIN, Juliana. Gerenciamento eletrônico de documentos na Universidade Federal de Santa Catarina, 2010. TCC (Curso de Biblioteconomia); com professora orientadora Prof. Eliana Bahia; KRÜGER, Júlia. Estágio Obrigatório I no Arquivo do DAP na Universidade Federal de Santa Catarina no $1^{\circ}$ semestre de 2016, com professora orientadora Aline Carmes Kurger. (Curso de Arquivologia). Portanto, as atividades desenvolvidas na DARQ promovem o conhecimento, a compreensão e a aplicação da teoria científica conexa à prática da documentação. Esperam-se ganhos acadêmicos para as áreas específicas de Ciências da Informação, Biblioteconomia e Arquivologia, no que concerne à produção de artigos, capítulos de livros, apresentações em eventos de modo a socializar o conhecimento.

\subsection{Indicação da coordenadora e dos possíveis participantes ou colaboradores}

Coordenadora: Professora Dra. Eliana Maria dos Santos Bahia Jacintho. Equipe da Divisão de Arquivo Central (Colaboradores). Douglas Aguiar das Neves (Técnico Administrativo e Chefe de Divisão); William Paiva (Arquivista), Rafael Silveira (Técnico Administrativo) Contato: (48) 3721-4280. e-mail: sa.dap@contato.ufsc.br. Os estudantes bolsistas são incluídos conforme as disponibilidades dos recursos. Nomes e cursos são definidos conforme a demanda, considerando o perfil social e econômico dos estudantes e principalmente que bolsas de pesquisa e ensino (monitoria) não podem ser contempladas na primeira fase dos cursos. Trata-se de uma oportunidade de inclusão acadêmica e social aos participantes. Esse cenário reflete a contribuição do Departamento de Ciência da Informação na inclusão social e acadêmica dos alunos, possibilitando a 
realização de estágios pautados na experiência consolidada, que pode ser ampliada com a prática das ações, respaldadas pela teoria compreendida em sala de aula.

\subsection{Carga horária dos participantes}

A carga horária semanal alocada para a coordenadora do projeto é de 1 hora e solicita-se que seja constado no Plano de Trabalho do Departamento (PAD). Aos bolsistas participantes no projeto, carga horária de 20 horas semanais com o contrato perante a UFSC e conta com a colaboração do Servidor Técnico-Administrativo Sr. Douglas Aguiar das Neves, com 40 horas semanais. Ao final das atividades realizadas, há certificado de participação.

\subsection{Recursos financeiros potencialmente envolvidos}

Os recursos financeiros têm a sua gestão executada pela própria Universidade, mediante a Secretaria de Planejamento e Finanças ou por uma das fundações de apoio, devidamente credenciada. A atividade de coordenadora do projeto não é remunerada.

\subsection{Cronograma de execução das atividades}

\begin{tabular}{|l|c|c|c|c|c|c|}
\hline Período & \multicolumn{2}{|c|}{2016} & \multicolumn{2}{c|}{2017} & \multicolumn{2}{c|}{2018} \\
\hline Atividades & $\mathbf{1}$ & $\mathbf{2}$ & $\mathbf{1}$ & $\mathbf{2}$ & $\mathbf{1}$ & $\mathbf{2}$ \\
\hline Seleção de bolsistas & $\mathrm{x}$ & $\mathrm{x}$ & $\mathrm{x}$ & $\mathrm{x}$ & $\mathrm{x}$ & $\mathrm{x}$ \\
\hline Atividades de extensão & $\mathrm{x}$ & $\mathrm{x}$ & $\mathrm{x}$ & $\mathrm{x}$ & $\mathrm{x}$ & $\mathrm{x}$ \\
\hline
\end{tabular}

\begin{tabular}{|l|l|l|l|l|l|l|}
\hline $\begin{array}{l}\text { Disseminação dos } \\
\text { resultados: publicação de } \\
\text { textos, palestras, cursos }\end{array}$ & $\mathbf{x}$ & $\mathbf{x}$ & $\mathbf{x}$ & $\mathbf{x}$ & $\mathbf{x}$ & $\mathbf{x}$ \\
\hline $\begin{array}{l}\text { Redação do relatório } \\
\text { finalização do projeto }\end{array}$ & & & & & & \\
\hline
\end{tabular}

\subsection{Resultados a serem alcançados ou produtos esperados}

As atividades são executadas pelos bolsistas com a supervisão do servidor técnico-administrativo durante os semestres e espera-se alcançar os seguintes resultados:

a) Receber e arquivar documentos (atestados, portarias, memorandos, processos etc.) diariamente;

b) Organizar a documentação, com atividades de conferência 
e ordenação;

c) Fazer a higienização das pastas funcionais para digitalização;

d) Preparar e Digitalizar as pastas funcionais para indexação e registro nos softwares Nêutron e AFD/SIPEC;

e) Consultar as pastas funcionais e;

f) Realizar cópias dos documentos requeridos.

Os produtos oriundos da observação direta e indireta pautados na reflexão teórica podem gerar textos sobre a conservação e preservação da documentação do Arquivo da DARQ, para fins da memória institucional. O relatório final do projeto será efetuado, tendo em conta a proposta inicial apresentada pela coordenadora e a sua coerência com os objetivos e resultados alcançados durante a execução das atividades.

Espera-se obter dados relevantes para ampliação dos estudos científicos e acadêmicos, de forma que possa colaborar para a sociedade científica e divulgar em publicações científicas e eventos das áreas.

\subsection{Descrição do local}

As atividades dos bolsistas serão realizadas no Arquivo da DARQ pertencente ao Departamento de Administração de Pessoal (Prédio da Reitoria - Térreo (48) 3721-4280 E-mail: sa.dap@contato.ufsc.br) e também no Arquivo Central (Córrego Grande).

\subsection{Significado dos números localizados nas estantes do DARQ}

1 - Pastas Funcionais: toda massa documental produzida pelos servidores (ativos, inativos, dependentes e pensionistas), que têm matrícula acima de 120000.

- Classificação: Numérica (matrícula UFSC)

- Ordem: Inicia na pasta 01 (1 pasta matrícula 120019)

- Nome do Índice/Planilha: Planilha Lote 05

- Localização Índice/Planilha: Virtual/DARQ

- Higienizado: Alguns documentos

- Digitalizado: Alguns documentos

- Nêutron: Sim

- Caixa: Vermelha / Papelão

2 - Ofícios: criados pela UFSC ou por outros órgãos que se 
referem a mais de um servidor.

- Classificação: Ano

- Ordem: Caixa $01-03$

- Nome do Índice/Planilha: Ofícios_Amarelo

- Localização Índice/Planilha: Virtual/DARQ/Planilhas

- Higienizado: Nenhum

- Digitalizado: Nenhum

- Nêutron: Não

- Caixa: Poliondas / Cinza

3 - Portarias: criados pela UFSC ou por outros órgãos que se referem a mais de um servidor.

- Classificação: Ano

- Ordem: Caixa 01 - 03

- Localização Índice/Planilha: Portarias

- Localização Planilha: Virtual/DARQ/Portarias

- Higienizado: Não

- Digitalizado: Portarias2009-2015 / Virtual/DARQ/Portarias

- Nêutron: Não

- Caixa: Poliondas / Amarelo

4 - Fichas Financeiras: fichas financeiras criadas de 1976 a 1987.

- Classificação: Alfabética

- Ordem:

- Nome do Índice/Planilha: Caixa ficha financeira (feita só até Azomar Francisco Lopes)

- Localização Índice/Planilha: Virtual/DARQ/Planilhas/Planilhas DARQ

- Higienizado: Não

- Digitalizado: Não

- Nêutron: Não

- Caixa: Papelão

5 - Fichas de Registros de Funcionários (Ficha Amarela): fichas amarelas ou brancas referentes aos registros de contratação dos funcionários antes de 1990. Documentos de servidores sem matrícula do ETUSC.

- Classificação: Alfabética

- Ordem: 01 - 17

- Nome do Índice/Planilha: Ficha de registro de 
empregados_ETUSC

- Localização Î́ndice/Planilha:

Virtual/DARQ/Planilhas/Planilhas DARQ

- Higienizado: Não

- Digitalizado: Não

- Nêutron: Não

- Caixa/Cor: Papelão

6 - Lei $n^{\circ}$ 1711: planilhas de cálculo referentes à Lei $n^{\circ} 1711 . /$ Todos os documentos estão indexados no NÊUTRON / Físico está no Arquivo Central.

- Classificação: Alfabética

- Ordem: 01 - 08

- Nome do Índice/Planilha: Lei n¹711

- Localização Índice/Planilha: Virtual/DARQ/Planilhas

- Higienizado: Sim

- Digitalizado: Sim

- Nêutron: Sim

- Caixa/Cor: Poliondas/Vermelho

7 - Processos SICAJ: Processos Judiciais

- Classificação: pelo número do SICAJ

- Ordem: 01 - 17

- Nome do Índice/Planilha: Processo SICAJ_Vermelho

- Localização Índice/Planilha: Virtual/DARQ/Planilhas

- Higienizado: Não

- Digitalizado: Não

- Nêutron: Não

- Caixa: Papelão

8 - Processos Judiciais 1987 - 2013: processos criados por Divisões, Departamentos, Centros, Sindicatos e outros órgãos. Documentos Físicos estão no Arquivo Central.

- Classificação: Ano

- Ordem:

- Nome do Índice/Planilha: Índice Processos Judiciais

- Localização Índice/Planilha: Virtual/DARQ/Planilhas

- Higienizado: Não

- Digitalizado: Não

- Nêutron: Não 
- Caixa: Papelão

9 - Memorandos: criados pela UFSC ou por outros órgãos que se referem a mais de um servidor.

- Classificação: Ano

- Ordem:

- Nome do Índice/Planilha:Índice Memorando

- Localização Índice/Planilha: Virtual/DARQ/Planilhas

- Higienizado: Não

- Digitalizado: Não

- Nêutron: Não

- Caixa: Poliondas / Amarelo

10 - Serviço Voluntário 2000 - 2013: Processos referentes aos professores que prestam, voluntariamente, serviços à UFSC. Todos os documentos estão indexados no NÊUTRON / Documentos Físicos estão no Arquivo Central.

- Classificação: Ano

- Ordem: Alfabética

- Nome do Índice/Planilha: Processos Serviço Voluntário verde

- Localização Índice/Planilha: Virtual/DARQ/Planilhas

- Higienizado:Sim

- Digitalizado: Sim

- Nêutron: Sim

- Caixa/Cor: Poliondas / Vermelho

11 - Serviço Voluntário 2014 - 201-: Processos referentes aos professores que prestam, voluntariamente, serviços à UFSC.

- Classificação: Ano

- Ordem: Alfabético

- Nome do Índice/Planilha: Processos Serviço Voluntário verde

- Localização Índice/Planilha: Virtual/DARQ/Planilhas

- Higienizado: Não

- Digitalizado: Não

- Nêutron: Não

- Caixa/Cor: Poliondas/Vermelho

12 - Boletim de Frequência: frequência mensal dos servidores 
ativos enviados pelos Departamentos. Todos os documentos estão digitalizados em PDF e na Pasta Boletim de Frequência no Virtual.

Os boletins de Frequência ficam arquivados temporariamente numa pasta durante 2 meses para o total recebimento das frequências. Apenas depois, o documento é inserido no Índice/ Planilha e Digitalizado.

- Classificação: Mês

- Ordem: Numérica

- Nome do Índice/Planilha: Boletim de Frequência

- Localização Índice/Planilha: Virtual/DARQ/Boletim de Frequência

- Higienizado:

- Digitalizado: Sim/PDF/ Virtual/DARQ/Boletim de Frequência

- Nêutron: Não

- Caixa/Cor: Poliondas / Amarela

13 - Recadastramento 2014 - 201-: Comprovantes de recadastramento apresentados pelos servidores aposentados e pensionistas.

- Classificação: Ano

- Ordem: Alfabético

- Nome do Índice/Planilha:

- Localização Índice/Planilha: Virtual/DARQ/Planilhas

- Higienizado: Não

- Digitalizado: Não

- Nêutron: Não

- Caixa/Cor: Poliondas / Azul.

\section{CONCLUSÃO}

Por fim, a Digitalização e Higienização da documentação na Divisão de Arquivo do DAP/PRODEGESP/UFSC é um projeto ainda em andamento, mas cumpre os objetivos propostos. O aluno, ao final da atividade, terá habilidade de manipular documentos arquivísticos e noção da importância de se ter a teoria arrolada com a prática, para a consolidação da profissão. A instituição ganha com a conservação e preservação da documentação do Arquivo da $\mathrm{DARQ}$, para fins da memória institucional.

Portanto, como mencionado acima, as atividades desenvolvidas na DARQ servirão para promover o conhecimento, a compreensão e a aplicação da teoria científica conexa à prática da 
documentação. Ganhando, assim, as áreas específicas de Ciências da Informação, Biblioteconomia, Arquivologia e Museologia, no que concerne à produção de artigos, capítulos de livros, apresentações em eventos, de modo a socializar o conhecimento.

Recebido em: 24 mar. 2018. Aceito em: 06 set. 2018.

\section{REFERÊNCIAS}

BRASIL. Decreto $n^{\circ} 8.539$ de 8 de outubro de 2015. Dispõe sobre o uso do meio eletrônico para a realização do processo administrativo no âmbito dos órgãos e das entidades da administração pública federal direta, autárquica e fundacional. Disponível em <http://www.planalto.gov.br/ccivil_03/_Ato20152018/2015/Decreto/D8539.htm>. Acesso em: 10 out. 2017.

BRASIL. Lei n. 12.527, de 18 de novembro de 2011. Dispõe sobre a política nacional de arquivos públicos e privados. Disponível em: <http://www.planalto.gov.br/ccivil_03/_ato2011- 2014/2011/lei/l12527.htm>. Acesso em: 09 out. 2017.)

BRASIL. Lei n. 8.159, de janeiro de 1991. Dispõe sobre a Política Nacional de Arquivos Públicos e dá outras providências. Brasília, DF: Senado; 1991. Disponível em: <http://www.planalto.gov.br/ccivil_03/leis/L8159.htm >. Acesso em: 10 out. 2017.

CHAGAS, Magda Teixeira; BAHIA, Eliana Maria dos Santos. Desenvolvimento, conservação e recuperação das coleções. Florianópolis: CIN/CED/UFSC, 2010. 118 p.

CUNHA, Murilo Bastos da; CAVALCANTI, Cordélia Robalinho de Oliveira. Dicionário de Biblioteconomia e Arquivologia. Brasília, DF: Briquet de Lemos/Livros, 2008.

FACHIN, Juliana. Gerenciamento eletrônico de documentos na Universidade Federal de Santa Catarina, 2010. TCC (Curso de Biblioteconomia); orientadora Prof. Eliana Bahia. Disponível em: https://repositorio.ufsc.br/handle/123456789/120709. Acesso em: 12 out. 2017.

KRÜGER, Júlia. Matriculada na disciplina Estágio Obrigatório I no Arquivo do DAP na Universidade Federal de Santa Catarina no $1^{\circ}$ semestre de 2016, com professora orientadora Aline Carmes Kurger. (Curso de Arquivologia).

LOPES, Luís Carlos. A nova arquivística na modernização administração. 2.ed. Brasília: Projecto Editorial/Annabel Lee, 2013.

MENEZES, Priscila Lopes. A conduta ética dos arquivistas participantes 
do Serviço de Informação ao Cidadão em universidades federais da Região Sul do Brasil. 2014. 249 p. Dissertação (Mestrado) - Universidade Federal de Santa Catarina, Centro de Ciências da Educação, Programa de Pós-Graduação em Ciência da Informação, Florianópolis, 2014. Disponível em: <http://tede.ufsc.br/teses/PCIN0111- D.pdf>. Acesso em 09 out. 2017.

NEVES, Douglas Aguiar das. A ergonomia no Arquivo do DAP na Universidade Federal de Santa Catarina, 2010. TCC (Curso de Biblioteconomia); orientadora Prof. Eliana Bahia.

REYZÁBAL, María Victoria. A comunicação oral e sua didática. Bauru: EDUSC, 1999. 355p.

UNIVERSIDADE FEDERAL DE SANTA CATARINA. Resolução normativa n. ${ }^{\circ}$ 03/CUN/09, de 08 de dezembro de 2009. Dispõe sobre as normas que regulamentam as ações de extensão na Universidade Federal de Santa Catarina. Disponível em:<http://proex.paginas.ufsc.br/files/2012/06/resoluC 3\%A7ao-normativa-003CUn2009.pdf>. Acesso em: 06 out. 2017. 